\title{
PREDIKSI JUMLAH PENERIMAAN SISWA SMK SWASTA TAHUN AJARAN 2011/2012
}

\author{
Haryadi Sarjono \\ Management Department, School of Business and Management, BINUS University \\ Jln. K.H. Syahdan No. 9, Kemanggisan-Palmerah, Jakarta Barat 11480
}

\begin{abstract}
This study aims to determine prediction number of modern private Vocational High School (SMK) students in a province in Borneo with the approach of six forecasting methods: Linear Regression, Exponential Smoothing with Trend, Exponential Smoothing, Weighted Moving Average, Moving Average, and the Naive Method, besides using Manual calculation, the approach of QM for windows is used as a comparison. The result will be determined by the six forecasting methods which is used as a proper basis for the next calculating based on the smallest MAD (Mean Absolute Deviation) and MSE (Mean Squared Error) approach. The data in this study were made by the writer alone.
\end{abstract}

Keywords: prediction of Vocational High School students, MAD, MSE, manual, QM for windows

\begin{abstract}
ABSTRAK
Penelitian ini bertujuan untuk mengetahui prediksi jumlah siswa Sekolah Menengah Kejuruan (SMK) swasta modern di sebuah propinsi di Kalimanatan dengan pendekatan enam metode forecasting yaitu Linear Regression, Exponential Smoothing With Trend, Exponential Smoothing, Weighted Moving Average, Moving Average, dan Nä̈ve Method, selain menggunakan perhitungan secara Manual juga menggunakan pendekatan QM for windows, sebagai perbandingan. Hasilnya akan ditentukan dari enam metode forecasting tersebut yang layak dipakai sebagai dasar perhitungan selanjutnya berdasarkan pendekatan MAD (Mean Absolute Deviation) dan MSE (Mean Squared Error) terkecil. Data dalam penelitian ini hanyalah rekayasa penulis semata.
\end{abstract}

Kata kunci: prediksi siswa SMK, MAD, MSE, manual, QM for windows 


\section{PENDAHULUAN}

SMK swasta modern merupakan salah satu SMK yang berada di sebuah provinsi di Kalimantan. Tabel 1 berikut ini adalah data penerimaan selama 6 tahun ajaran yang dimulai tahun ajaran 2005/2006 sampai 2010/2011.

Tabel 1 Penerimaan Siswa/i SMK Swasta Modern

\begin{tabular}{cc}
\hline Tahun Ajaran & Penerimaan Siswa/i \\
\hline $2005 / 2006$ & 459 \\
$2006 / 2007$ & 499 \\
$2007 / 2008$ & 486 \\
$2008 / 2009$ & 300 \\
$2009 / 2010$ & 482 \\
$2010 / 2011$ & 466 \\
$2011 / 2012$ & $?$ \\
\hline
\end{tabular}

Sumber: SMK Swasta Modern (2011) - rekayasa penulis

Dalam penelitian ini bertujuan untuk memprediksi penerimaan siswa SMK swasta modern tahun ajaran 2011/2012 dengan pendekatan menggunakan enam metode peramalan yang ada, antara lain: Linear Regression, Exponential Smoothing With Trend, Exponential Smoothing, Weighted Moving Average, Moving Average, dan Naïve Method.

Dari uraian diatas, berikut adalah masalah-masalah yang akan diselesaikan dalam penelitian ini, antara lain: 1) seberapa besar prediksi penerimaan siswa SMK swasta modern dengan pendekatan enam metode forecasting, dan 2) Dari enam metode forecasting yang dipakai, manakah yang mempunyai MAD dan MSE terkecil.

\section{Peramalan}

Menurut Heizer dan Render (2009: 162), peramalan (forecasting) adalah seni dan ilmu untuk memperkirakan kejadian di masa depan. Hal ini dapat dilakukan dengan melibatkan pengambilan data masa lalu dan menempatkannya ke masa yang akan datang dengan suatu bentuk model matematis. Menurut Assauri (1984) pada Hastarita (2008), Peramalan merupakan bagian awal dari suatu proses pengambilan suatu keputusan. Pujawan (2005: 87) menyatakan bahwa peramalan permintaan adalah kegiatan untuk mengestimasi besarnya permintaan terhadap barang barang atau jasa tertentu pada suatu periode dan wilayah pemasaran tertentu.

Menurut Santoso (2009: 7) definisi peramalan sebenarnya beragam, berikut beberapa definisi mengenai peramalan: perkiraan munculnya sebuah kejadian di masa depan, berdasarkan data yang ada di masa lampau; proses menganalisis data historis dan data saat ini untuk menentukan trend masa mendatang; proses estimasi dalam situasi yang tidak diketahui; pernyataan yang dibuat tentang masa depan; penggunaan ilmu dan teknologi untuk memperkirakan situasi di masa depan; upaya sistematis untuk mengantisipasi kejadian atau kondisi masa depan.

Dari beberapa definisi di atas, dapat disimpulkan bahwa peramalan berkaitan dengan upaya memperkirakan apa yang terjadi di masa depan, berbasis pada metode ilmiah (ilmu dan teknologi) serta dilakukan secara sistematis. 


\section{Menghitung Kesalahan Peramalan}

Menurut Heizer dan Render (2009: 165), ada 2 untuk menghitung forecast error, yaitu: pertama, Deviasi Rata-rata Absolut (Mean Absolute Deviation - MAD); MAD merupakan ukuran pertama kesalahan peramalan keseluruhan untuk sebuah model. Nilai ini dihitung dengan mengambil jumlah nilai absolut dari kesalahan peramalan dibagi dengan jumlah periode data (n).

$$
M A D=\frac{\sum \mid \text { permintaan aktual }- \text { peramalan } \mid}{n}
$$

Kedua, Kesalahan Rata-rata Kuadrat (Mean Squared Error - MSE); MSE merupakan cara kedua untuk mengukur kesalahan peramalan keseluruhan. MSE merupakan rat-rata selisih kuadrat antara nilai yang diramalkan dan yang diamati. Kekurangan penggunaan MSE adalah bahwa ia cenderung menonjolkan deviasi yang besar karen adanya pengkuadratan.

$$
M S E=\frac{\sum(\text { kesalahan peramalan })^{2}}{n}
$$

\section{METODOLOGI PENELITIAN}

Berikut adalah tabel metodologi penelitian ini.

Tabel 2 Metode Penelitian

\begin{tabular}{clll}
\hline No & \multicolumn{1}{c}{ Variabel } & \multicolumn{1}{c}{ Konsep Variabel } & \multicolumn{1}{c}{ Indikator Utama } \\
\hline 1 & Peramalan & $\begin{array}{l}\text { Predisksi penerimaan siswa } \\
\text { SMK }\end{array}$ & $\begin{array}{l}\text { Data penerimaan siswa SMK swasta Modern } \\
\text { dari tahun ajaran 2005/2006 - 2010/2011. }\end{array}$ \\
& \multirow{2}{*}{ Model Peramalan } & $\begin{array}{l}\text { Metode prediksi yang akan } \\
\text { diterapkan pada penelitian ini } \\
\text { di SMK swasta }\end{array}$ & $\begin{array}{l}\text { Linear Regression, Exponential Smoothing With } \\
\text { Trend, Exponential Smoothing, Weighted Moving } \\
\text { Average, Moving Average dan Nä̈ve Method. }\end{array}$ \\
& & $\begin{array}{l}\text { Ukuran akurasi hasil } \\
\text { peralaman }\end{array}$ & MAD dan MSE terkecil \\
& Hasil Peramalan & & \\
\hline
\end{tabular}

Sumber: Hasil pengolahan penulis (2012)

\section{HASIL DAN PEMBAHASAN}

\section{Forecasting Metode “Linear Regression”}

Secara Manual, berdasarkan data di atas, maka dapat ditentukan: a) prediksi penerimaan siswa (Ft) SMK tahun ajaran (2011/2012) dengan menggunakan pendekatan metode regresi linear / least square, b) penghitungan MAD dan MSE, seperti pada tabel 3 berikut: 
Tabel 3 Forecasting “Linear Regression”

\begin{tabular}{ccccccr}
\hline Tahun & Penerimaan $\mathbf{( F t )}$ & $\mathbf{X i}$ & $\mathbf{( X i )}(\mathbf{Y i})$ & $\mathbf{( X i}^{\mathbf{2}}$ & $\mathbf{F t}(\mathbf{4 2 8 , 5}+\mathbf{5 , 7 7 X})$ & $\mid \mathbf{Y t}-\mathbf{F t})$ \\
\hline $2005 / 2006$ & 459 & 1 & 459 & 1 & 434,27 & 24,73 \\
$2006 / 2007$ & 499 & 2 & 998 & 4 & 440,04 & 58,96 \\
$2007 / 2008$ & 486 & 3 & 1458 & 9 & 445,81 & 40,19 \\
$2008 / 2009$ & 300 & 4 & 1200 & 16 & 451,58 & 151,58 \\
$2009 / 2010$ & 482 & 5 & 2410 & 25 & 457,35 & 24,65 \\
$2010 / 2011$ & 466 & 6 & 2796 & 36 & 463,12 & 2,88 \\
\hline Total & $\mathbf{2 6 9 2}$ & - & $\mathbf{9 3 2 1}$ & $\mathbf{9 1}$ & - & $\mathbf{3 0 2 , 9 9}$ \\
\hline
\end{tabular}

Sumber: Hasil perhitungan penulis (2011)

$\mathrm{F}_{2011 / 2012}=463,12 \cong \mathbf{4 6 3}$ Siswa $/ \mathrm{i}$

$\mathbf{b}=\frac{6 \times 9321-21 \times 2692}{6 \times 91-21^{2}}=5,77 \quad a=\frac{2692}{6}-5,77 \times \frac{21}{6}=428,5$

$\mathbf{Y}=428,5+5,77 \quad$ dimana $\quad \mathbf{Y}_{7}=428,7+5,77 \times 7=3.039,89$

$\mathbf{M A D}=\frac{302,99}{6}=50,5983$ dan $\mathbf{M S E}=4.882,5849$

Secara program QM for Windows, hasil akhir menggunakan program QM for Windows, adalah sebagai berikut:

Tabel 4 Hasil Penghitungan dengan Program QM

\begin{tabular}{|c|c|c|c|c|c|c|c|c|}
\hline \multicolumn{9}{|c|}{ Jumlah Siswa SMK Swasta Modern Di Kalimantan Selatan Solution } \\
\hline & Demand(y) & $\operatorname{Time}(\mathrm{x})$ & $x^{\wedge} 2$ & $x^{*} y$ & Forecast & Error & |Error| & Error 2 \\
\hline $2005 / 2006$ & 459. & 1. & 1. & 459. & 464.238 & -5.238 & 5.238 & 27.437 \\
\hline $2006 / 2007$ & 499. & 2. & 4. & 998. & 457.6095 & 41.3905 & 41.3905 & $1,713.174$ \\
\hline $2007 / 2008$ & 486. & 3. & 9. & 1,458 & 450.9809 & 35.0191 & 35.0191 & $1,226.335$ \\
\hline $2008 / 2009$ & 300. & 4. & 16. & 1,200 . & 444.3524 & -144.3524 & 144.3524 & $20,837.6$ \\
\hline $2009 / 2010$ & 482. & 5. & 25. & 2,410 . & 437.7238 & 44.2762 & 44.2762 & $1,960.38$ \\
\hline $2010 / 2011$ & 460. & 6. & 36. & 2,760 . & 431.0952 & 28.9048 & 28.9048 & 835.4849 \\
\hline TOTALS & 2,686 & 21. & 91. & 9,285 & & 0.0001 & 299.1809 & $26,600.42$ \\
\hline AVERAGE & 447.6667 & 3.5 & 15.1667 & $1,547.5$ & & 0. & 49.8635 & $4,433.403$ \\
\hline Next period forecast & & & & & 424.4667 & (Bias) & (MAD) & (MSE) \\
\hline Intercept & 470.8666 & & & & & & Std err & 81.5482 \\
\hline Slope & -6.6286 & & & & & & & \\
\hline
\end{tabular}

\section{Forecasting Metode “Exponential Smoothing with Trend”}

Secara manual, berdasarkan data di atas, maka dapat ditentukan: a) prediksi penerimaan siswa (Ft) SMK tahun ajaran 2011/2012 dengan menggunakan pendekatan metode exponential smoothing with trend dengan asumsi $\mathrm{F} 1=459, \mathrm{~T} 1=0, \alpha=0,3$ dan $\beta=0,2$ dan b) penghitungan MAD dan MSE nya, dimana untuk penentuan $(\alpha)$ dan $(\beta)$ tidak ada ketentuannya, dalam soal ini penentuan $(\alpha=$ $\mathbf{0 , 3})$ dan $(\boldsymbol{\beta}=\mathbf{0 , 2})$ hanya rekayasa penulis, kita bisa menentukan sendiri berapa $(\alpha)$ dan berapa $(\boldsymbol{\beta})$ 
Tabel 5 Forecasting "Exponential Smoothing with Trend"

\begin{tabular}{|c|c|c|c|c|}
\hline Tahun & Periode & Penerimaan (Yt) & \multicolumn{2}{|c|}{ Ft } \\
\hline $2005 / 2006$ & 1 & 459 & \multicolumn{2}{|l|}{ - } \\
\hline $2006 / 2007$ & 2 & 499 & \multicolumn{2}{|c|}{$0,3 \times 459+0,7 \times(459+0)=459$} \\
\hline $2007 / 2008$ & 3 & 486 & \multicolumn{2}{|c|}{$0,3 \times 499+0,7 \times(459+0)=471$} \\
\hline $2008 / 2009$ & 4 & 300 & \multicolumn{2}{|c|}{$0,3 \times 486+0,7 \times(471+2,4)=477,18$} \\
\hline $2009 / 2010$ & 5 & 482 & \multirow{3}{*}{\multicolumn{2}{|c|}{$\begin{array}{l}0,3 \times 300+0,7 \times(477,18+1,62)=425,16 \\
0,3 \times 482+0,7 \times(425,16+9,108)=448,5876 \\
0,3 \times 466+0,7 \times(448,5876+0039)=521,7140\end{array}$}} \\
\hline $2010 / 2011$ & 6 & 466 & & \\
\hline $2011 / 2012$ & 7 & - & & \\
\hline Tahun & Periode & Penerimaan (Yt) & \multicolumn{2}{|l|}{ Tt } \\
\hline $2005 / 2006$ & 1 & 459 & \multicolumn{2}{|l|}{-} \\
\hline $2006 / 2007$ & 2 & 499 & \multicolumn{2}{|c|}{$0,2 \times(459-459)+0,8 \times 0=0$} \\
\hline $2007 / 2008$ & 3 & 486 & \multicolumn{2}{|c|}{$0,2 \times(471-459)+0,8 \times 0=2,4$} \\
\hline 2008/2009 & 4 & 300 & \multicolumn{2}{|c|}{$0,2 \times(477,18-471)+0,8 \times 2,4=1,62$} \\
\hline 2009/2010 & 5 & 482 & \multicolumn{2}{|c|}{$0,2 \times(425,16-477,18)+0,8 \times 1,62=9,108$} \\
\hline 2010/2011 & 6 & 466 & \multirow{2}{*}{\multicolumn{2}{|c|}{$\begin{array}{r}0,2 \times(448,5876-425,16)+0,8 \times 9,108=97,0039 \\
0,2 \times(521,7140-448,5876)+0,8 \times 97,0039= \\
92,2283 \\
\end{array}$}} \\
\hline $2011 / 2012$ & 7 & - & & \\
\hline Tahun & Periode & Penerimaan $(\mathbf{Y t})$ & $\mathbf{F I T}=\mathbf{F t}+\mathbf{T t}$ & $|\mathbf{Y t}-\mathbf{F I T}|$ \\
\hline $2005 / 2006$ & 1 & 459 & - & - \\
\hline $2006 / 2007$ & 2 & 499 & 459 & 40 \\
\hline $2007 / 2008$ & 3 & 486 & 473,4 & 2,6 \\
\hline 2008/2009 & 4 & 300 & 478,8 & 178,8 \\
\hline 2009/2010 & 5 & 482 & 434,268 & 47,732 \\
\hline 2010/2011 & 6 & 466 & 545,5915 & 79,5915 \\
\hline $2011 / 2012$ & 7 & - & 613,9423 & - \\
\hline & & Total & \multicolumn{2}{|r|}{348,7235} \\
\hline
\end{tabular}

Sumber: Hasil perhitungan penulis (2012)

a. $\mathrm{F}_{2011 / 2012}=613,9423 \cong \mathbf{6 1 4} \mathrm{Siswa} / \mathrm{i}$

b. $\mathrm{MAD}=\frac{348,7235}{5}=\mathbf{6 9 , 7 4 4 7}$

MSE $=\frac{40^{2}+2,6^{2}+178,8^{2}+47,732^{2}+79,5915^{2}}{5}=\mathbf{8 . 4 3 7 , 8 7 0 1}$

Secara program QM for Windows, hasil akhir menggunakan program QM for Windows, adalah seperti tabel 6 berikut.

Tabel 6 Hasil Penghitungan dengan Program QM Jumlah Siswa SMK Swasta Modern di Kalimantan Selatan

\begin{tabular}{l|r|r|r|r|r|r|r} 
& Demand(y) & $\begin{array}{r}\text { unadjusted } \\
\text { forecast }\end{array}$ & trend & $\begin{array}{r}\text { adjusted } \\
\text { forecast }\end{array}$ & error & Error) & Errorn2 \\
\hline $2005 / 2006$ & 459. & 459 & 0 & & & & \\
\hline $2006 / 2007$ & 499. & 459. & 0 & 459. & 40. & 40. & $1,600$. \\
\hline $2007 / 2008$ & 486. & 471. & 2.4 & 473.4 & 12.6 & 12.6 & 158.7601 \\
\hline $2008 / 2009$ & 300. & 477.18 & 3.156 & 480.336 & -180.336 & 180.336 & $32,521.07$ \\
\hline $2009 / 2010$ & 482. & 426.2352 & -7.6642 & 418.571 & 63.429 & 63.429 & $4,023.232$ \\
\hline $2010 / 2011$ & 460. & 437.5997 & -3.8584 & 433.7413 & 26.2587 & 26.2587 & 689.5192 \\
\hline TOTALS & $2,686$. & & & & -38.0483 & 322.6237 & $38,992.58$ \\
\hline AVERAGE & 447.6667 & & & & -7.6097 & 64.5247 & $7,798.517$ \\
\hline Next period forecast & & 441.6189 & -2.2829 & 439.336 & (Bias) & (MAD) & (MSE) \\
\hline & & & & & & Std err & 114.0067
\end{tabular}




\section{Forecasting Metode “Exponential Smoothing”}

Secara manual, berdasarkan data di atas, maka dapat ditentukan: a) prediksi penerimaan siswa (Ft) SMK tahun ajaran 2011/2012 dengan pendekatan metode exponential smoothing dimana $\alpha=0,3$ dan $\mathrm{F} 1=215$, b) penghitungan MAD dan MSE.

Tabel 7 Forecasting “Exponential Smoothing”

\begin{tabular}{|c|c|c|c|c|}
\hline Tahun & Periode & Penerimaan (Yt) & Ft & $|\mathbf{Y t}-\mathbf{F t}|$ \\
\hline $2005 / 2006$ & 1 & 459 & - & - \\
\hline $2006 / 2007$ & 2 & 499 & $459+0,3 \times(459-459)=0$ & 40 \\
\hline $2007 / 2008$ & 3 & 486 & $459+0,3 \times(499-459)=471$ & 15 \\
\hline $2008 / 2009$ & 4 & 300 & $471+0,3 \times(486-471)=475,51$ & 175,51 \\
\hline $2009 / 2010$ & 5 & 482 & $475,5+0,3 \times(300-475,5)=422,85$ & 59,15 \\
\hline $2010 / 2011$ & 6 & 466 & $422,85+0,3(482-422,85)=439,995$ & 26,01 \\
\hline 2011/2012 & 7 & - & $439,995+0,3(466-439,995)=447,7965$ & - \\
\hline \multicolumn{4}{|c|}{ Total } & 316,005 \\
\hline
\end{tabular}

Sumber: Hasil perhitungan penulis (2012)

a. $\quad F_{2011 / 2012}=447,7965 \cong 448$ Siswa/i

b. $\mathrm{MAD}=\frac{316,005}{5}=\mathbf{6 3 , 2 0 1}$ dan

$$
\mathrm{MSE}=\frac{40^{2}+15^{2}+175,5^{2}+59,15^{2}+26,005^{2}}{5}=7.360,04
$$

Secara program QM for Windows, hasil akhir menggunakan program QM for Windows, adalah seperti pada tabel 8 berikut.

Tabel 8 Hasil Penghitungan dengan Program QM Jumlah Siswa SMK Swasta Modern di Kalimantan Selatan

\begin{tabular}{|l|r|r|r|r|r|} 
& Demand(y) & Forecast & Error & Error| & Errorn2 \\
\hline $2005 / 2006$ & 459 & 459 & & & \\
\hline $2006 / 2007$ & 499 & 459. & 40. & 40. & $1,600$. \\
\hline $2007 / 2008$ & 486. & 471. & 15. & 15. & 225. \\
\hline $2008 / 2009$ & 300. & 475.5 & -175.5 & 175.5 & $30,800.25$ \\
\hline $2009 / 2010$ & 482. & 422.85 & 59.15 & 59.15 & $3,498.722$ \\
\hline $2010 / 2011$ & 460. & 440.595 & 19.405 & 19.405 & 376.554 \\
\hline TOTALS & $2,686$. & & -41.945 & 309.055 & $36,500.53$ \\
\hline AVERAGE & 447.6667 & & -8.389 & 61.811 & $7,300.105$ \\
\hline Next period forecast & & 446.4165 & (Bias) & (MAD) & (MSE) \\
\hline & & & & Std err & 110.3034 \\
\hline
\end{tabular}




\section{Forecasting metode “Weighted Moving Average"}

Secara manual, berdasarkan data di atas, maka dapat ditentukan: a) prediksi penerimaan siswa (Ft) pada tahun 2011/2012 dengan metode weighted moving average dimana ditentukan bobotnya sebesar 0,2; 03; dan 0,5 b) penghitungan MAD dan MSE.

Tabel 9 Forecasting "Weighted Moving Average”

\begin{tabular}{ccccc}
\hline Tahun & Periode & Penerimaan $(\mathbf{Y t})$ & $\mathbf{F t}$ & $|\mathbf{Y t}-\mathbf{F t}|$ \\
\hline $2005 / 2006$ & 1 & 459 & - & - \\
$2006 / 2007$ & 2 & 499 & - & - \\
$2007 / 2008$ & 3 & 486 & - & - \\
$2008 / 2009$ & 4 & 300 & $(0,2 \times 459+0,3 \times 499+0,5 \times 486)=484,5$ & 184,50 \\
$2009 / 2010$ & 5 & 482 & $(0,2 \times 499+0,3 \times 486+0,5 \times 300)=395,6$ & 86,41 \\
$2010 / 2011$ & 6 & 466 & $(0,2 \times 486+0,3 \times 300+0,5 \times 482)=428,2$ & 37,81 \\
$2011 / 2012$ & 7 & - & $(0,2 \times 300+0,3 \times 482+0,5 \times 466)=437,6$ & - \\
& & Total & & 308,72 \\
\hline
\end{tabular}

Sumber: Hasil perhitungan penulis (2012)

a. $F_{2011 / 2012}=437,6 \cong \mathbf{4 3 8}$ siswa

b. $\mathrm{MAD}=\frac{308,7}{3}=\mathbf{1 0 2 , 9}$ dan $\mathrm{MSE}=\frac{184,5^{2}+86,4^{2}+37,8^{2}}{3}=\mathbf{1 4 , 2 5 9 , 5}$

Secara program QM for Windows, hasil akhir menggunakan program QM for Windows, adalah sebagai berikut.

Tabel 10 Hasil Penghitungan dengan Program QM Jumlah Siswa SMK Swasta Modern di Kalimantan Selatan

\begin{tabular}{|c|c|c|c|c|c|}
\hline & Demand(y) & Forecast & Error & |Error| & Errorn2 \\
\hline $2005 / 2006$ & 459. & 459. & & & \\
\hline 2006/2007 & 499. & 459. & 40. & 40. & 1,600 \\
\hline $2007 / 2008$ & 486. & 471. & 15. & 15. & 225 \\
\hline $2008 / 2009$ & 300. & 475.5 & -175.5 & 175.5 & $30,800.25$ \\
\hline $2009 / 2010$ & 482. & 422.85 & 59.15 & 59.15 & $3,498.722$ \\
\hline 2010/2011 & 460. & 440.595 & 19.405 & 19.405 & 376.554 \\
\hline TOTALS & 2,686 & & -41.945 & 309.055 & $36,500.53$ \\
\hline AVERAGE & 447.6667 & & -8.389 & 61.811 & $7,300.105$ \\
\hline \multirow[t]{2}{*}{ Next period forecast } & & 446.4165 & (Bias) & $(M A D)$ & (MSE) \\
\hline & & & & Std err & 110.3034 \\
\hline
\end{tabular}

\section{Forecasting metode "Moving Average"}

Secara Manual, berdasarkan data diatas, tentukanlah: a) prediksi penerimaan siswa (Ft) pada tahun 2011/2012 dengan metode moving average dengan $n=3$ ? b) penghitungan MAD dan MSE. 
Tabel 11 Forecasting “Moving Average”

\begin{tabular}{ccccc}
\hline Tahun & Periode & Penerimaan $(\mathbf{Y t})$ & Forecast $(\mathbf{F t})$ & $\mid$ Yt - FtI \\
\hline $2005 / 2006$ & 1 & 459 & - & - \\
$2006 / 2007$ & 2 & 499 & - & - \\
$2007 / 2008$ & 3 & 486 & - & - \\
$2008 / 2009$ & 4 & 300 & $(459+499+486): 3=481,34$ & 181,33 \\
$2009 / 2010$ & 5 & 482 & $(499+486+300): 3=428,34$ & 53,67 \\
$2010 / 2011$ & 6 & - & $(300+482+466): 3=416,00$ & - \\
$2011 / 2012$ & 7 & Total & & \multicolumn{2}{c}{$\mathbf{2 7 8 , 3 3}$} \\
\hline
\end{tabular}

Sumber: Hasil perhitungan penulis (2012)

a. $\mathrm{F}_{2011 / 2012}=\mathbf{4 1 6}$ Siswa

b. $\mathrm{MAD}=\frac{278,33}{3}=\mathbf{9 2 , 7 7 2}$

$\operatorname{MSE}=\frac{181,333^{2}+53,667^{2}+43,33^{2}}{3}=\mathbf{1 2 . 5 4 6 , 4 3 4}$

Secara program QM for Windows, hasil akhir menggunakan program QM for Windows, adalah sebagai berikut.

Tabel 12 Hasil Penghitungan dengan Program QM

Jumlah Siswa SMK Swasta Modern di Kalimantan Selatan

\begin{tabular}{|l|r|r|r|r|r|} 
& Demand(y) & Forecast & Error & Eerror| & Error 22 \\
\hline $2005 / 2006$ & 459 & & & \\
\hline $2006 / 2007$ & 499. & & & & \\
\hline $2007 / 2008$ & 486. & & & & \\
\hline $2008 / 2009$ & 300 & 481.3333 & -181.3333 & 181.3333 & $32,881.78$ \\
\hline $2009 / 2010$ & 482. & 428.3333 & 53.6667 & 53.6667 & $2,880.11$ \\
\hline $2010 / 2011$ & 460. & 422.6667 & 37.3333 & 37.3333 & $1,393.776$ \\
\hline TOTALS & $2,686$. & & -90.3334 & 272.3333 & $37,155.67$ \\
\hline AVERAGE & 447.6667 & & -30.1111 & 90.7778 & $12,385.22$ \\
\hline Next period forecast & & 414. & (Bias) & (MAD) & (MSE) \\
\hline & & & & Std err & 192.7581 \\
\hline
\end{tabular}

\section{Forecasting metode "Naive Method"}

Secara manual, berdasarkan data di atas, tentukanlah: a) prediksi penerimaan siswa (Ft) pada tahun 2011/2012 dengan metode naive method, b) penghitungan MAD dan MSE.

Tabel 13 Forecasting "Naive Method"

\begin{tabular}{ccccc}
\hline Tahun & Periode & Penerimaan $(\mathbf{Y t})$ & $\mathbf{F t}=\mathbf{Y t}-\mathbf{1}$ & Yt - FtI \\
\hline $2005 / 2006$ & 1 & 459 & - & - \\
$2006 / 2007$ & 2 & 499 & 459 & 40 \\
$2007 / 2008$ & 3 & 486 & 499 & 13 \\
$2008 / 2009$ & 4 & 300 & 486 & 186 \\
$2009 / 2010$ & 5 & 482 & 300 & 182 \\
$2010 / 2011$ & 6 & 466 & 482 & 16 \\
$2011 / 2012$ & 7 & - & 466 & - \\
& & Total & & $\mathbf{4 3 7}$ \\
\hline
\end{tabular}

Sumber: Hasil perhitungan penulis (2012) 
a. $\quad \mathrm{F}_{2011 / 2012}=\mathbf{4 6 6} \mathrm{Siswa} / \mathrm{i}$

b. $\quad \mathrm{MAD}=\frac{437}{5}=\mathbf{8 7 , 4}$

MSE $=\frac{40^{2}+13^{2}+186^{2}+182^{2}+16^{2}}{5}=\mathbf{1 3 . 9 4 8}$

Secara program QM for Windows, hasil akhir menggunakan program QM for Windows, adalah sebagai berikut.

Tabel 12 Hasil Penghitungan dengan Program QM Jumlah Siswa SMK Swasta Modern di Kalimantan Selatan

\begin{tabular}{|l|r|r|r|r|r|}
\hline & Demand(y) & Forecast & Error & |Error| & Error 2 \\
\hline $2005 / 2006$ & 459. & & & & \\
\hline $2006 / 2007$ & 499. & 459. & 40. & 40. & $1,600$. \\
\hline $2007 / 2008$ & 486. & 499. & -13. & 13. & 169. \\
\hline $2008 / 2009$ & 300. & 486. & -186. & 186. & $34,596$. \\
\hline $2009 / 2010$ & 482. & 300. & 182. & 182. & $33,124$. \\
\hline $2010 / 2011$ & 460. & 482. & -22. & 22. & 484. \\
\hline TOTALS & $2,686$. & & 1. & 443. & $69,973$. \\
\hline AVERAGE & 447.6667 & & 0.2 & 88.6 & $13,994.6$ \\
\hline Next period forecast & & 460. & (Bias) & (MAD) & (MSE) \\
\hline & & & & Std err & 152.7231 \\
\hline
\end{tabular}

Berikut ini adalah tabel dan gambar hasil rekapitulasi prediksi penerimaan siswa di SMK Swasta Modern di Kalimantan Selatan.

Tabel 8 Rekapitulasi Prediksi Penerimaan Siswa di SMK Swasta Modern

\begin{tabular}{clrrr}
\hline NO & \multicolumn{1}{c}{ Forecasting } & MAD & \multicolumn{1}{c}{ MSE } & Hasil Prediksi \\
\hline 1 & Linear Regression & 50,49 & $4.882,58$ & 463,11 \\
2 & Exponential Smooting With Trend & 69,74 & $8.437,87$ & 613,94 \\
3 & Exponential Smooting & 63,21 & $7.360,04$ & 447,79 \\
4 & Weighted Moving Average & 102,90 & $14.259,51$ & 437,61 \\
5 & Moving average & 92,77 & $12.546,43$ & 416,00 \\
6 & Naïve Method & 87,41 & $13.948,42$ & 466,00 \\
\hline
\end{tabular}

Sumber: Hasil perhitungan penulis (2012) 


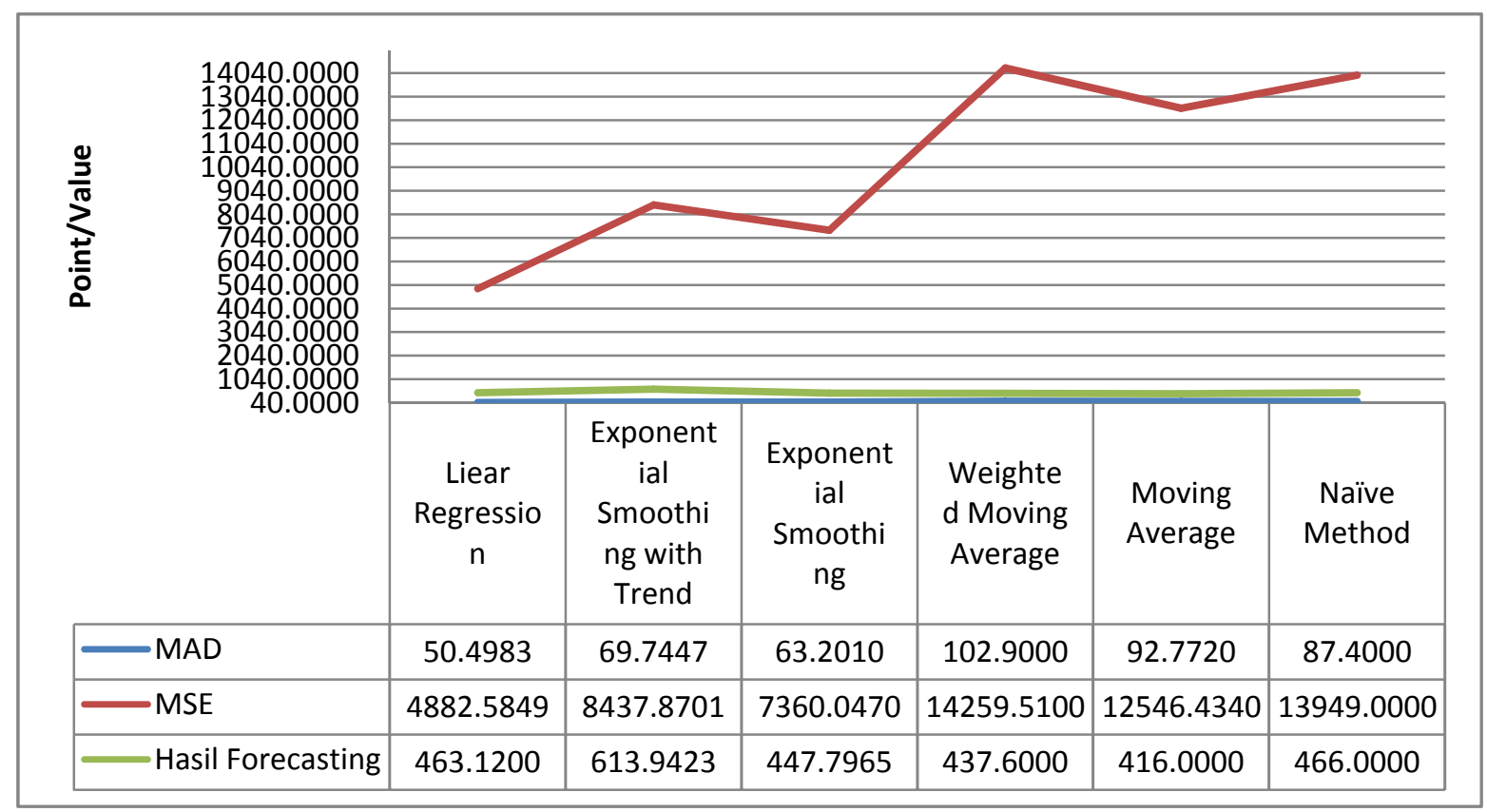

Gambar 1 Hasil Rekapitulasi Prediksi SMK Swasta Modern

Jadi, dari hasil perhitungan forecasting didapat hasil MAD dan MSE yang terkecil pada metode Linear Regression yaitu MAD sebesar 50,4983 dan MSE sebesar 4.882,5849. Untuk perhitungan selanjutnya menggunakan data dari metode forecasting Linear regression menghasilakn forecast 463 siswa. Hasil perhitungan manual dan QM for Windows mungkin saja berbeda karena adanya pembulatan pada perhitungan manual.

\section{SIMPULAN}

Dari hasil perhitungan secara manual dibandingkan dengan menggunakan program QM for windows, terhadap prediksi penerimaan siswa SMK swasta modern tahun ajaran 2011/2012 sebesar 463 siswa, dimana prediksi ini menggunakan 6 metode forecasting, yaitu Linear Regression, Exponential Smoothing With Trend, Exponential Smoothing, Weighted Moving Average, Moving Average dan Naïve Method, ternyata metode Linear Regression/Least Squares menghasilkan MAD dan MSE terkecil, yaitu 50,4983 dan 4.882,58. 


\section{DAFTAR PUSTAKA}

Anderson, Sweeney, Williams, Martin. (2008). Quantitative Methods for Business. International Student Edition. Eleventh Edition. Canada: South-Western Cengage Learning.

Hanke, J. E., and Wichern, D. W. (2005). Business Forecasting. Eighth Edition. New Jersey: Pearson Prentice Hall.

Heizer, J., dan Render, B. (2009). Manajemen Operasi, (terjemahan), Buku 1, Edisi 9, Jakarta: Salemba Empat.

Pramesti, G. (2009). Buku Pintar, Minitab 15. Jakarta: Elex Media Komputindo.

Render, B., Ralph M, Stair Jr, and Hanna, Michael E, (2006), Quantitative Analysis for Management, International Edition, Pearson Prentice Hall, USA,

Santoso, S. (2009). Business Forecasting, Metode Peramalan Bisnis Masa Kini dengan MINITAB dan SPSS. Jakarta: Elex Media Komputindo.

Sarjono, H. (2010). Aplikasi Riset Operasi. Jakarta: Salemba Empat.

Taylor, B. W. (2010), Introduction to Management Science. Tenth Edition. New Jersey: Pearson.

Wongso, T. (2012). Optimalisasi Penentuan Rute dengan Pendekatan Forecasting dan Metode Distribusi Saving Matrix Serta Perancangan Sistem Informasi Pendistribusian Barang Pada Tirta Bintaro”, Skripsi Manajemen - Sistem Informasi, Universitas Bina Nusantara, Jakarta Barat.

http://www,ittelkom,ac,id/library/index,php?view=article\&catid=25\%3Aindustri\&id=258\%3Ametode -peramalan-forecasting-method\&option=com_content\&Itemid=15 